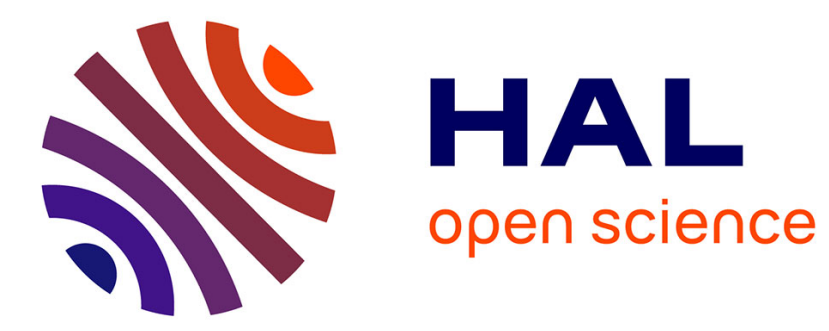

\title{
PLM for Education. The Next Generation of Engineers
} Andrés Padillo, Jesus Racero, Jose Carlos Molina, Ignacio Eguía

\section{To cite this version:}

Andrés Padillo, Jesus Racero, Jose Carlos Molina, Ignacio Eguía. PLM for Education. The Next Generation of Engineers. 15th IFIP International Conference on Product Lifecycle Management (PLM), Jul 2018, Turin, Italy. pp.327-337, 10.1007/978-3-030-01614-2_30 . hal-02075598

\section{HAL Id: hal-02075598 \\ https://hal.inria.fr/hal-02075598}

Submitted on 21 Mar 2019

HAL is a multi-disciplinary open access archive for the deposit and dissemination of scientific research documents, whether they are published or not. The documents may come from teaching and research institutions in France or abroad, or from public or private research centers.
L'archive ouverte pluridisciplinaire HAL, est destinée au dépôt et à la diffusion de documents scientifiques de niveau recherche, publiés ou non, émanant des établissements d'enseignement et de recherche français ou étrangers, des laboratoires publics ou privés.

\section{(c)(1)}

Distributed under a Creative Commons Attribution| 4.0 International License 


\title{
PLM for education. The next generation of engineers
}

\author{
Andrés Padillo ${ }^{1}$, Jesús Racero ${ }^{1}$, Jose Carlos Molina ${ }^{1}$, Ignacio Eguía ${ }^{1}$ \\ ${ }^{1}$ Universidad de Sevilla \\ Andrespadillo88@gmail.com,jrm@us.es,jmolina12@us.es, ies@us.es
}

\begin{abstract}
Industry of the Future (IoF) or Industry 4.0 is bringing a new model of industry wherein it is necessary to acquire new skills by the new generation of engineering students.

The following paper pursues as a main objective the design and implementation of a new subject for students of Engineering at the University of Sevilla (Spain). In this subject, fundamentals aspect of PLM business models and engineering relationship are collected, and students are equipped of necessary knowledges and skills to customize PLM tools according to business requirements. As a practical application, students must undertake a real case based on a collaborative engineering study between design and manufacturing areas.

To achieve this goal, software architecture is described and provided to students for the management, configuration and industrialization of the data product, as well as the assignment of the tasks necessary to successfully achieve the different milestones involved in the project. This work describes the tools used to implement a practical application: ARAS INNOVATOR as PLM software, a LEGO product as DMU (Digital Mock-Up) and Redmine for project management.
\end{abstract}

Keywords: PLM Tools, Education, Collaborative Engineering, Industry 4.0.

\section{Introduction}

The globalisation of markets and rapid changes experienced by the industry through digital transformation are bringing significant changes in how to design and manufacture products, where the collaborative engineering plays an essential role.

The use of PLM tools to manage lifecycle is essential to achieve success and more and more of European companies increasing use of them. As a result demand has heightened significantly over the last several years. However, lack of professional skilled specialized in this area in order to respond companies requirements is limited. 
In Spain, nowdays the use of PLM is based on different roles associated to several CAx PLM tools. However, does not exist a role or a specific profile such a PLM engineer to interact with the different tools each other and customize them according to business models requirements.

Actually, many of PLM courses are focus on the design of products and processes, using the standard configuration provided by software default. However, it is very difficult to find any company whose needs can fit the software.

The new generation of PLM systems allows a great customization and parameterization, enabling its adaptation to any business process and company. This competence has not been exploited, although it more is demanded every day.

Based on this problematic, arise an initiative to include in engineering studies subjects related to PLM Systems where collected fundamental requirements that should fullfill a PLM engineer to design and customize the systems according to business requirements.

The following paper describes the design, deployment and results achieved of introduction and customization PLM skills into aeronautical education engineering. The desired aim are cover knowledge:

- Concepts and fundamentals of the PLM systems and its iteraction with engineering

- PLM Tools \& customization

- A use case based on acquired skills

- Evaluation methods

This paper is organized as follows. Section 2 introduces others experience into PLM training into higher education, it focus on skill and curriculum. Section 3 describes competence or skills, design of contents, hardware architecture and evaluation method. Section 4 shows the deployment experience and the results. Finally, the paper presents the conclusions obtained.

\section{$2 \quad$ Pedagogical renewal. PLM \& Industry 4.0}

PLM systems are solutions that seek to manage the product life cycle and allow the companies connect all information improving the operational efficiencies as well as working faster (recovery and exchange of electronic information, reuse of data, automated capabilities, and data security).

PLM is not only a software. When a PLM System is described, must support business solutions in collaborative creation, management and product and process definition. In Industries PLM is commonly used for:

- Centralize and organize product data

- Design \& management product development projects

- Integrate design process \& industrialization

PLM systems aim to connect and cover the entire cycle of a product (From conception to market debut). A set tools that provide a platform through a collaborative envi- 
ronment to optimize flow and information Exchange between different actors involved in lifecycle.

To achieve this purpose, these tools have the ability to customize and model their data, which allows companies to adapt them according to the different requirements of the business ([7]).

Currently, this is a gap to cover nowadays between industry and PLM systems. The lack of consultants and training engineers in this area makes it difficult a correct implementation and execution of PLM systems in a company.

From different educational institutions as well as PLM software companies are beginning to promote the use of CAX-PLM tools through subjects and training courses focusing on using tools to became a professional PLM engineer.

With that aim, in 2016 the project named 'Accelerating the adoption of Industry of the Future (IoF) supporting technologies by Spanish universities'; was launched. It is an educational project, with a focus on manufacturing related competences and partially funded by La Fondation Dassault Systèmes ([10]).

Current educational cases dealing with CAX-PLM technologies in some spanish universities:

- University Jaume I of Castellón. The educational model is based on projects or module assignments that integrate several courses. This case comprises a training module on the methodological use of CAX applications, integrating the product design and development process with a PLM application to support the collaborative teamwork ([11];[12]).

- University of Cádiz. The I4.0 support technologies dealing with CAD/CAM/CAE and PDM/PLM systems are within the scope of the Manufacturing Processes Engineering Area [10].

- Polytechnic University of Madrid - Industrial Engineering School. Currently, in the Degree and Master studies, only different CAX applications are used in different courses.

Therefore, there is no an integrating solution, based also on the use of a PLM system and the customization, that allows students developing a multidisciplinary collaborative project.

The aim of the project called ProVerStand ("Produktentwicklung über Verteilte Standorte" - "Product Development Involving Distributed Locations") is to provide universities and similar institutions access to state of the art PLM systems, such as PDMS, CAE and CAD ([4]). The Project defines a PLM scenario from preparatory level to master level (Figure 1). 


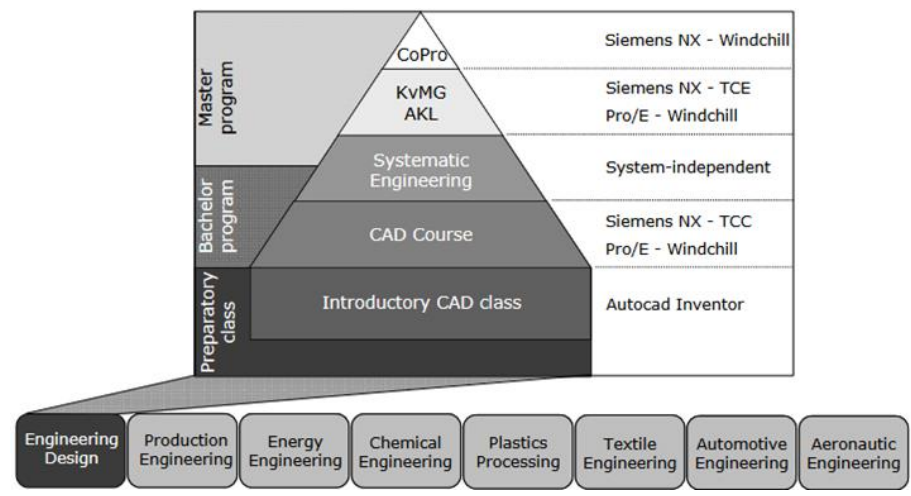

Fig. 1. PLM education scenario ([4])

Research Institute of Aoyama Gakuin University in Japan has developed effective educational curriculum. The goal of this lesson is an understanding of effective PLM when a new product is developed using e-Learning as the educational tool ([6]). The training focus on the business processes in PLM, designs the curriculum of the PLM education by e-Learning.

The content is structure in 5 subjects where it develop the following concepts: Product Design (EBOM), production design (Layout \& systems production) production management (MRP,Material Requeriments Planning) and process design.

The faculty at Purdue University has been working together to reform existing PLM-related courses. The new curriculum provides three courses at junior years to build a student's basic PLM knowledge and skill sets and two senior level electives course based on project-based learning environment to help the students synthesize what they have learned during the past academic years ([3]).

The importance of include trends of industry 4.0 in the engineering trainning, is reflected in different courses in several European universities: the polytechnic university of Torino ([2]) developing courses around the framework Small Factory Project. The courses focus on training the students in ERP and PLM tools.

The HSR (university of applied science of Rapperswil)([14]) covers trends of industry $4.0 \&$ digitalization based on a scenario around the product using very common technologies (Lego, Arduino, etc) and IT tools (PLM, CAD, ERP, etc)

Finally, it is note that in the literature review a training destined to customize PLM system based on customer requirements was not found.

This gap is taken advantage for design and implement a new subject with a first approach to cover these requirements.

\section{Design and Development of a PLM subject}

The incipient demand on PLM \& Industries 4.0 has seduced students and therefore engineering schools to include PLM training in their curricula. All this is encouraged because the A400M program will further strengthen the importance of Andalusia (in 
the south of Spain) as one of the country's main aerospace-production regions. The all-new A400M military aircraft made its first flight from Andalusia's Seville San Pablo Airport after its assembly at the EADS CASA factory, the third largest Airbus production plant in the world.

The Andalusian aerospace cluster is composed of 117 companies (engineering and consulting $18.8 \%$ ), generating 14.463 direct jobs. Where $26 \%$ are highly qualified employees (Engineers).

This environment has led to develop an optional subject in the aeronautical engineering master degree at the University of Sevilla. In order to provide students of cross-cutting skills to plan, design, manage \& certification procedures, infrastructures and systems that support the aerospace industry with activities related to industry 4.0. As well as specific skills related to use and customization of PLM tools focus on development of business in professional field.

As a prerequisite, the student must be graduated in an engineering field and is hihgly recommended possess knowledges of data modeling and production management.

With a total of 125 hours distributed as face-to-face classes and cooperative homework, the subject is divided into two blocks:

- Theorical classes: teaching class $25 \mathrm{~h}$ (face to face) and 50 hours analysis and study ( non-presential)

- Computing practices: teaching class $15 \mathrm{~h}$ (Face to face) and $35 \mathrm{~h}$ (non presential)

The structure of the subject is divided in four large modules. Each module in turn, is structured into theoretical and applied sub-modules. The first one, is composed by an introductory part and general concepts associated with the relevant module and the second one by a practical part. In such a way that the student progressively acquires the skills necessary for each of them.

Module 1: Product lifecycle management in aerospace industry.

Theoretical part: Introduction and basic concepts about product lifecycle. Differences between sequential engineering and concurrent engineering and first approach concept of collaborative engineering across PLM systems. Definition of PLM system and their relationship with the Industy 4.0.

Practical part: Analyze and develop with a project management tool a collaborative framework collecting the following aspects:

- Project management

- Teamwork management

- System virtualization concept, software and PLM architecture

Module 2: PLM System in aerospace industry

Theoretical part: Introduction and concepts about PLM Systems in aerospace industry. Programs and projects management in aerospace industry. Main activities:

- Planning, managing and controlling

- Organizational structure OBS and WorkBreakdownStructure Work. 
- Requeriments management \& product specification.

Practical part: Design and modeling an aerospace program with several projects associated with a PLM tool where it is collected the following aspects:

- Analysis of requirements associated with the project

- OBS (Organizational Breakdown Structure) the structure of the project

- Analysis and modeling users permissions in the tool

- Creation of identities

- Modify permissions and users

- Update items and relationships

- Allocation and configuration of roles in the teamwork

Module 3: Product data management

Theoretical part: Introduction and concepts of industrial digital mock-up (iDMU, [9]): 3D virtual prototypes and information contain. Product data management: concept of BOM, EBOM, MBOM. Configuration management, versions and variants \& Product lifecycle management.

Practical part: Design and modeling a product lifecycle with a PLM tool where it is collected the following aspects:

- Set the product lifecycle \& models

- Products and models creation

- Definition states and permission associated with states

- Creation of bill of material BOM

- Creation new attributes

Module 4:Process data management in PLM environment

Theoretical part: Introduction and concepts about virtual product and colaborative design. Definition of a process management data and process plan. The concept of PPR (Product, Process, Resource) structure and data explode in the manufacturing area (Work instructions and Maintain Resource Operation)

Practical part: Design, modeling and adapt a process plan in a PLM tool where it is collected the following aspects:

- Setting up the environment to include the concept of PPR in a tool

- Design data model and implementation of a classical PPR structure and relationships between Product, Process and Resource) 


\section{Case Study. Configuration \& customization a PLM tool}

\subsection{Architecture software}

For the implementation and development of practices, it is necessary to set up an infrastructure allowing the student to interact with the different tools in a collaborative framework through two main systems: a production system that allows students to work in a collaborative environment for the implementation project and a development system, through a virtual machine in each student machine for developing and testing solutions. Previous implementation in the productive system (figure 2).

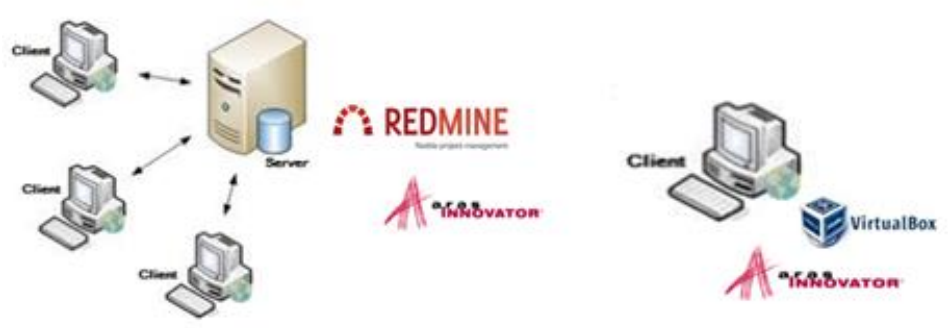

Fig. 2. Architecture software

\subsection{Software and Material support}

The Information systems, material and complementary information used in practice are described below:

- ARAS INNOVATOR is a software, which offers integration services for PLM and PDM solutions on a single platform.

The structure is divided in 3 mains modules:

- PLM to manage processes throughout the life cycle

- PDM to manage CAD data : product, part and documentation

- PLATFORM to adapt, extend and build applications

- Redmine is a free and open source, web-based project management and issue tracking tool. It allows users to manage multiple projects and associated subprojects. It features per project wikis and forums, time tracking, and flexible, rolebased access control. It includes a calendar and Gantt charts to aid visual representation of projects and their deadlines. Redmine integrates with various version control systems and includes a repository browser and diff viewer.( Kanai, 2013)

- A Lego helicopter model 6745-H, composed by 247 pieces, to define the assembly process (6745 Model Propeller, [1]). The implementation must be defined in the Aras Innovator tool under the Schema control of the production model defined 
as well as Lego designer software tool (Lego Designer, [8]), a free software available for mac and windows to design through the pc any Lego assembly.

\subsection{Rubric Evaluation.}

A rubric is typically an evaluation tool or set of guidelines used to promote the consistent application of learning expectations, learning objectives, or learning standards in the classroom, or to measure their attainment against a consistent set of criteria. In instructional settings, rubrics clearly define academic expectations for students and help to ensure consistency in the evaluation of academic work from student to student, assignment to assignment, or course to course.

The rubric applied has 9 points. From 1 to 6 evaluate the PLM skills achieve in the subject. The $7^{\text {th }}$ and $8^{\text {th }}$ point is an optional section to increase marks and the last point evaluates project management skills.

The practical part is developed in groups. The groups consist of a minimum of 3 students and a maximum of 4 . Each group defines a project manager who manages and monitors tasks for a satisfactory conclusion.

\section{1st point collected the sections related to the OBS structure and will be assessed} the following aspects:

- User definition: the student must define different roles.

- Teamwork definition: the student must define different groups that share common functions.

- Permission definition: The student must define permissions according to the role, lifecycle and data type associated.

\section{2nd point collected the sections related to the program \& project management} and will be assessed the following aspects:

- Program definition. The student must define at least one program and define lifecycle (state, transition) and the users and permissions involved.

- Project definition. The student must define a project based on a template that should be extended with tasks and activities. The project must be associated with a model as well as a life cycle and access permissions.

\section{3rd point includes paragraphs related to the customization of a PLM tool:}

- Parts and Products definition: the student must define new attributes to the structure of a Part, identify the types of parts and design forms \& new attributes.

- Definition of the life cycle: the student must design a cycle of life for each item type as well as the permissions and allocation of transitions.

4th point includes the concept of EBOM (As Design concept). 
- Definition of the EBOM where the student must design the product structure with a LEGO model and implementation into PLM System.

- Definition the Vault File concept applying import and export data associated to parts.

$5^{\text {th }}$ point It is used to define the Manufacturing model (as planned and as prepare structure), design of the manufacturing structure (MBOM)

- Definition and design manufacturing parts, implementing the idmu data model into PLM system.

- Definition of the MBOM structure for 6745 Lego propeller model. The student must incorporate new structures in the PLM tool (processes and resources) as well as define their lifecycle, forms and relationships between elements (structure PPR).

$6{ }^{\text {th }}$ point Documentation of the technical evaluation report: the student must upload documentation associated with the project that reflects the following aspects:

- Introduction and objectives

- Scope

- Analysis and requirements capture

- Design

- Implementation

- Tests

- Conclusions

- Extensions

$7^{\text {th }}$ point an alternative option for students. It evaluates the automatic software programming included into PLM System. For example, develop import and export data in batch modes.

- Definition data model. Description of the level of implementation of the description of the procedures.

$\mathbf{8}^{\text {th }}$ point: included aspect related to extensions where the student puts to the test the skills acquired going a step and beyond.

- Design and implementation Work Instruction.

- Engineering change order. Definition business process to change management.

- Effectivities

$\mathbf{9}^{\text {th }}$ point collected aspects of project management. To know the activities done by students in the subject.

- Work distribution. Hours to develop task.

- Task type distribution. Balanced work distribution by rubric point.

- Analysis learning curves. Evaluation of group members. 


\subsection{Results.}

In the literature review, the experience is focusing on describing content and skills acquired by the students.

This experience starts in 16/17 academic year. The following table describes the level of achievement in percentage (by work team) of competencies acquired by students.

$\begin{array}{lrrrrrrrr}\text { Work Team } & 1 & 2 & 3 & 4 & 5 & 6 & 7 & 8 \\ 1 & 1,0 & 1,00 & 1,00 & 1,00 & 1,00 & 1,00 & 1,00 & 0,50 \\ 2 & 1,0 & 1,00 & 1,00 & 1,00 & 0,89 & 1,00 & 0,50 & 0,00 \\ 3 & 1,0 & 1,00 & 1,00 & 1,00 & 1,00 & 1,00 & 1,00 & 0,75 \\ 4 & 1,0 & 1,00 & 1,00 & 1,00 & 0,56 & 1,00 & 0,00 & 0,25 \\ 5 & 1,0 & 0,67 & 0,71 & 0,67 & 0,89 & 1,00 & 0,00 & 0,25 \\ 6 & 1,0 & 1,00 & 1,00 & 1,00 & 0,89 & 1,00 & 0,00 & 0,25 \\ 7 & 1,0 & 1,00 & 1,00 & 1,00 & 1,00 & 1,00 & 0,00 & 0,25 \\ 8 & 1,0 & 1,00 & 1,00 & 1,00 & 0,89 & 1,00 & 0,00 & 0,00 \\ \text { Average } & 1,0 & 0,96 & 0,96 & 0,96 & 0,89 & 1,00 & 0,31 & 0,28\end{array}$

Fig. 3. Comparative table (expressed as a percentage)

The results reflect that all Works teams have acquired $75 \%$ of competences defined. Likewise, these competencies have been achieved completing over $80 \%$ of activities.

On the other hand, software development skills that involves using customization PLM Tools and not included in theoretical lessons and practices, have not been achieved. One of the possible causes is the dedication time at developing competences and skills. The average dedicated by the Works teams was 156 hours; 45hours theoretical-practical and 116 for developing out of classes.

A dissagregate analysis, student by student, shows that the workload is balanced. The difference between the hardworker is around $11 \%$ while the deviation respect from the average stands is about $8 \%$. The work division has been balanced (deviation less than $15 \%$ )

\section{Conclusions}

This paper has described the development and results of the implementation of a subject oriented towards the acquisition of skills in the customization of PLM systems. A very demanded area nowadays by companies and not included in the current aeronautical engineering curricula.

During the design and the planning stages of the subject, several doubts emerged about the reception from the students as an optional subject with unknown content.

However, the result reflected in the information systems of the University of Sevilla through satisfactions surveys, shows that not only the subject has well accepted by 
the students but also the number of students has doubled respect from the last course and assessed positively in the study plans.

Finally, another important factor to consider and perhaps the most important from the point of view as educator have been the result reflected in the workload required to the student outside school hours. It can be observed the similarity between the estimated and actual hours in the study plan and how the most of students have achieved the aims and competences successfully.

\section{$6 \quad$ References}

1. 6745 Propeller Model Instructions. LEGO (https://www.lego.com/en/us/service/buildinginstructions/search?initialsearch=6745\#?text=6745). Last Accessed 17/03/2018.

2. Bedolla J, D’Antonio Gianluca, Chiabert P., A Novel Approach for Teaching IT Tools within Learning Factories, Procedia Manufacturing, Volume 9, 2017, Pages 175-181. ISSN 2351-9789.

3. Chang,Y. and Miller, PLM Curriculum Development: Using an Industry-Sponsored Project to Teach Manufacturing Simulation in a Multidisciplinary Environment. C. Dept. of Computer Graphics Technology, Purdue University, West Lafayette, Indiana, USA. Journal of Manufacturing Systems Vol. 24/No. 3

4. Feldhusen J., M. Löwer, A. Brezing, J. Neis, in DS 62: Proceedings of E and PDE 2010, the 12th International Conference on Engineering and Product Design Education - When Design Education and Design Research Meet

5. Kanai, K , Anderson M. edmine as a Web-Based Collaboration Tool in Engineering Design Courses. $120^{\text {th }}$ ASEE Annual Conference \& Exposition. 2013

6. Kakehi, M., Yamada, T., \& Watanabe, I. (2009). PLM education in production design and engineering by e-Learning. International Journal of Production Economics, 122(1), 479484. https://doi.org/10.1016/j.ijpe.2009.06.028

7. Javvadi, Lakshminadh. (2011). Product life cycle management An introduction.

8. Lego Designer Software. (https://www.lego.com/en-us/ldd). Last Accessed 17/03/2018.

9. Mas, Fernando \& Luis Menendez, Jose \& Servan, J \& Gomez, Alex \& Rios, Jose. (2012). Aerospace industrial digital mock-up exploitation to generate assembly shopfloor documentation.

10. Ríos J. et al., "Accelerating the Adoption of Industry 4.0 Supporting Technologies in Manufacturing Engineering Courses", Materials Science Forum, Vol. 903, pp. 100-111, 2017

11. Vila C., et al., Project-based collaborative engineering design and manufacturing learning with PLM tools, Cooperative Design, Visualization, and Engineering, (2009) 367-371. Springer.

12. Vila C. et al., Collaborative product development experience in a senior integrated manufacturing course, Intl J. of Engineering Education, 25 (2009) 886-899.

13. Yoga, J., PLM based Customization for Extraction of NX Assembly from Team center to Local Drive. International Journal of Applied Information Systems (IJAIS) -ISSN: 22490868 Foundation of Computer Science FCS, New York, USA Volume 2-No.6, May2012 www.ijais.org

14. Fradl B., Sohrweide A., Nyffenegger F. (2017) PLM in Education - The Escape from Boredom. In: Ríos J., Bernard A., Bouras A., Foufou S. (eds) Product Lifecycle Management and the Industry of the Future. PLM 2017. IFIP Advances in Information and Communication Technology, vol 517. Springer, Cham 